\title{
A VILA, A COLÔNIA E O MUNICÍPIO: A ORGANIZAÇÃO DO ESPAÇO PRUDENTOPOLITANO E OS LIMITES DA INTEGRAÇÃO ÉTNICA ${ }^{1}$
}

\author{
El Pueblo, la Colonia y el Municipio: la Organización del Espacio \\ Prudentopolitano y los Límites de la Integración Étnica
}

\author{
Odinei Fabiano RAMOS \\ Universidade Estadual do Centro-Oeste - UNICENTRO \\ odineiramos@unicentro.br \\ https://orcid.org/0000-0002-8682-5542
}

\begin{abstract}
RESUMO: A premissa é compreender a construção do espaço territorial do município de Prudentópolis-PR e a influência da política de terras na constituição sociedade prudentopolitana. Entende-se que tal sociedade formou-se como um amálgama cultural formulado pela cumplicidade adquirida por grupos étnicos distintos, mesmo através da rejeição ao outro. Seria importante entender, então, as fronteiras identitárias não como uma forma de rejeitar a identidade do outro, mas sim a de negociar os quadros representativos que irão definir a construção de uma nova identidade, pautada na integração étnica. Percebe-se, em Prudentópolis, a existência de uma hegemonia étnica e que definiu as representações coletivas constituintes do imaginário popular. Tais representações constituíram, através do processo de negociação da identidade, na integração de grupos étnicos antes vistos como antagônicos, o ucraniano e o polonês. Tal trabalho visa demonstrar que a formação do município de Prudentópolis constituiu elementos suficientes para compreender as negociações dessa(s) identidade(s). PALAVRAS-CHAVE: Fronteira étnica; Identidade; Imigração Ucraniana; Prudentópolis
\end{abstract}

RESUMEN: La premisa es comprender la construcción del espacio territorial del municipio de Prudentópolis-PR y la influencia de la política de tierras en la constitución de la sociedad local. Se entiende que dicha sociedad se formó como una fusión cultural formulada por la complicidad adquirida por diferentes grupos étnicos, incluso a través del rechazo del otro. Sería importante comprender, entonces, los límites de identidad no como una forma de rechazar la identidad del otro, sino para negociar los marcos representativos que definirán

\footnotetext{
${ }^{1}$ A discussão aqui apresentada foi iniciada na minha dissertação de mestrado intitulada Ucranianos, poloneses e "brasileiros" em Prudentópolis-PR
} 
la construcción de una nueva identidad, basada en la integración étnica. En Prudentópolis, se percibe la existencia de una hegemonía étnica que define las representaciones colectivas que constituyen la imaginación popular. Dichas representaciones constituyeron, a través del proceso de negociación de identidad, la integración de grupos étnicos previamente vistos como antagónicos, el ucraniano y el polaco. Tal trabajo tiene como objetivo demostrar que la formación del municipio de Prudentópolis constituyó elementos suficientes para comprender la negociación de esta (estas) identidad (es). PALABRAS CLAVE: frontera étnica; Identidad; Inmigración Ucraniana; Prudentópolis

\section{MOTIVAÇÕES DA (RE) ORGANIZAÇÃO DO ESPAÇO PRUDENTOPOLI- TANO}

Espaço de sociabilidade ${ }^{2}$ : conceito que por vezes parece ser um adjetivo básico atríbuído a locais e períodos em que distintos grupos étnicos se fazem presentes. Tal característica encontra formas e valores distintos quando pensada a partir do contexto do espaço de análise. Prudentópolis pode ser usado como um exemplo. Localizado na região centro-sul do Paraná, a 200 quilômetros da capital, o município tem em sua formação ingredientes que transformaram os diferentes espaços de fronteira em formas de integração étnica. Isso se deve ao fato de que, em findos do século XIX, o lugar foi organizado para garantir o processo de colonização do espaço paranaense. Nesse local, então pertencente ao município de Guarapuava, inicia-se uma experiência de imigração eslava.

Inúmeros foram os motivos e interesses que levaram governos e instituições a constituir fatores de atração a diferentes grupos étnicos, tendo a Lei de Terras de 1850 como marco. Foi a partir dela que o foi constituída uma política imigratória para atrair mão de obra estrangeira, a qual encontrou no Paraná fatores que facilitaram sua disseminação. Como passava pelo processo de emancipação, o Paraná necessitava preencher os vazios demográficos como uma das justificativas à sua separação da Província de São Paulo. A ocupação deveria ser rápida e efetiva, sendo a criação de colônias de imigrantes europeus a saída que garantiria esse resultado. A criação das colônias de imigrantes se torna política de governos como informados nos relatórios de presidentes de província a partir de 1853 .

Os espaços vazios não eram os únicos motivos para a ocupação da região. Era

\footnotetext{
${ }^{2} \mathrm{O}$ espaço de sociabilidade pode ser compreendido como local, no sentido amplo da palavra, onde ocorrem a "produção, reprodução e desenvolvimento das sociedades, apresentando-se como um espaço em contínua transformação, quer do ponto de vista dos processos socioculturais, quer da reflexão que sobre ele se faz".(MENEZES, 2000: p. 163)
} 
necessária mão de obra adequada, mas não qualquer uma. Além de laborioso o grupo imigrante deveria atender um requisito que, aos territórios do sul, pareciam básicos: a cor da pele. Logo após o término do período escravagista, o império se preocupou em formar/ transformar o uma situação que o incomodava: o número de negros. Segundo Dreher (1995, p. 71) "no início do século XIX, a população brasileira é constituída de um milhão de indígenas, (...) um milhão novecentos e oitenta e sete mil negros, em sua maioria absoluta escravos, e 628.000 mil mestiços. [...] Os brancos somam 845.000".

A hipótese sustentada por Dreher, evidente que não a única, é que uma das causas maior na imigração geralmente não é objeto de estudos migratórios: o branqueamento da raça (DREHER, 1995, p. 71) ou caiamento da população (WACHOWICZ, 2010, p. 173)

O temor era de que o número de negros suscitasse uma série de revoltas (como já estava acontecendo) e que esse quadro criasse a transformação da identidade nacional ainda em construção em uma identidade baseada e fundamentada na africana. Seguindo essa afirmação a política imigratória busca atrair imigrantes de preferência europeus com o intuito de branquear a população brasileira. (RAMOS, 2012). A chegada de grupos eslavos era, no caso de Prudentópolis dentre outros na região, uma forma de branqueamento racial, numa tentativa de transformar o fenótipo do povo brasileiro. Tal situação fez com que a formação do estado paranaense fosse constituída pela variedade de grupos étnicos dispostos próximos um ao outro.

É nesse contexto que a região que futuramente seria chamada de Prudentópolis ${ }^{3}$ vinha sendo transformada. Ficam evidentes tais modificações quando em 1882 iniciou-se a abertura de uma linha telegráfica.

Os trabalhos de prolongamento da linha telegraphica d'esta capital ao interior da Província começarão no mez de Junho do corrente anno, tendo-se explorado até esta data 250 kilometros sendo 120 kilometros de traçado para a linha de Curytiba á Palmeira e o ramal para á Lapa, e 130 kilometros de Santa Cruz á Guarapuava. Este ultimo traçado, foi estudado de maneira a poder acompanhal-o (sic) uma estrada de rodagem em condições favoráveis, necessitando menos desenvolvimento do que qualquer outro projecto apresentado até hoje para o mesmo fim. Passa por Cupim, transpõe a serra da Ribeira n'uma depressão baixa, atravessa a vargem do Rio dos Patos, em cujas mattas vive uma população numerosa, galga a serra da Esperança ao lado esquerdo do Rio S. João única vereda que serve para subir essa serra difficil. (RELATÓRIO, 1882, p. 74)

\footnotetext{
${ }^{3}$ A vila, pertencente a Guarapuava se chamava São João do Rio Claro e posteriormente São João de Capanema, em homenagem ao engenheiro que ali se hospedara.
} 
Foi as margens dessa linha que o vilarejo começa a se desenvolver. Destacou-se, nessa localidade, a figura de Firmo Mendes de Queiroz, proprietário de terras e comerciante que, ao doar terras para a construção de uma igreja, contribui para a transformação do local.

O Senhor Firmo de Queiroz, morador de Guarapuava, adquiriu uma parte do registro de terras de S. João do Rio Claro e estabeleceu-se com sua família à beira de um riacho sem nome, hoje rio Caxim, e ali deu início a um pequeno povoado. O Senhor Firmo de Queiroz era um bandeirante de São Paulo. Após deixar sua cidade natal, veio com seus pais para Guarapuava mais ou menos no ano de 1875-6. No remoto sítio S. João do Rio Claro, longe da cidade, a morada de Firmo de Queiroz, qual oásis no meio a terras desertas do extenso município de Guarapuava, servia de abrigo a viandantes que se dirigiam a Guarapuava ou Curitiba. (POCZENCK, 1998, p. 17)

Os acontecimentos do vilarejo ocorriam na região que tinha como pontos centrais a capela, a casa comercial e a hospedagem de Firmo Mendes, o qual demonstrava bom fluxo entre os agentes políticos da região. Era ali que os viajantes se hospedavam, como o Barão de Capanema, que recebeu de Firmo o pedido de interceder junto ao então Presidente Prudente de Morais que enviasse colonos para a região. A região pouco se desenvolveu, pelo menos até a intervenção do governo federal que em 1894 começou a divisão de lotes.

Felizmente os Poderes do Estado, comprehendendo toda a importância da colonisação nas circunstâncias actuais do paiz, e vendo malogradas as diversas tentativas, que se tem feito em vários pontos do Império no intento de promover a emigração, habilitarão o governo imperial com amplos meios para cuidar desse ramo do serviço, a que o mesmo governo acaba de dar valioso impulso, celebrando com a Associação Central de Colonização um contracto, pelo qual se abriga a importar avultado numero de colonos. Contemos pois com a paternal solicitude do governo imperial, e a Ella reunindo os recursos de que podemos dispor, vermos aproximar a epocha que tanto desejamos. (RELATÓRIO, 1858, p. 21) 


\section{OS IMIGRANTES E OS "DO LOCAL": CONTATO INEVITÁVEL}

Com a chegada das famílias imigrantes em $1896^{4}$, o aumento populacional finalmente ocorreu, mas isso não significou necessáriamente uma concentração de índivíduos próxima a região central da vila.

Num primeiro momento, as famílias ucranianas ficaram concentradas próximas a vila, mas como vieram para trabalhar a terra, foram transferidas para a zona rural. Vale reforçar que os grupos de imigrantes vieram atraídos pela propagranda do governo federal que seduziu imigrantes pela fartura de terras e pela necessidade de mão de obra. Parecia ser essa uma motivação de mão dupla: o estado precisava de mão de obra e o imigrante o acesso a terra.

Por orientação do Governo Federal, as terras destinadas a colônia de imigrantes foi dividida em linhas que obedeciam a um sistema geométrico definido com área aproximada de 10 alqueires cada. Essa simetria demonstra que a distribuição de terras se deu de forma organizada 5 .

Chegaram aproximadamente 1500 famílias, o que numericamente tornava os ucranianos na maior grupo étnico na região, maior inclusive do que os brasileiros $^{6}$. Mesmo sendo maioria, os imigrantes não puderam interferir na configuração toponímica instituída, pois a rede de poder já havia se estabelecido há tempos, como entre Firmo Mendes de Queiroz e os representantes do governo. Assim os brasileiros dominavam o cenário político da Vila de Prudentópolis. Tal hegemonia, gradativamente resultou num clima de rivalidade entre ucranianos e brasileiros. A essa equação também foi adicionada a figura do imigrante polonês, que também foi alocado em Prudentópolis, pois os agentes de imigração do Governo Federal acreditavam se tratar do mesmo grupo

\footnotetext{
${ }^{4}$ De acordo com Burko, (1963) foi no dia 16 de abril de 1896 que chegaram à região que futuramente se chamaria Prudentópolis as carroças de Henrique Kremmer trazendo as primeiras famílias de imigrantes ucranianos, os quais foram encaminhados à região pelo serviço imigratório do Paraná. Foi então que o diretor das obras públicas e coloniais, o engenheiro civil Dr. Cândido Ferreira de Abreu, resolveu por denominar a colônia de imigrantes eslavos de Prudentópolis, em homenagem ao então presidente da República Dr. Prudente de Moraes (CAMARGO, 1929).

${ }^{5}$ Segundo Hauresko (2002) as comunidades recebem o nome de linhas pela sua disposição padronizada no território prudentopolitano, sendo as casas construídas em filas em ambos os lados da estrada e em alguns casos em comunidades-núcleos onde se encontra uma aglomeração demográfica.
}

6 "Brasileiros" foi como, a princípio, eram chamados os do lugar: indígenas, negros e brancos que não ucranianos 
étnico dos ucranianos ${ }^{7}$. Cabe relembrar que os poloneses formaram o maior contingente de imigrantes do Paraná e mesmo sendo minoria em Prudentópolis tinham uma relevante rede de relacionamentos frente ao Governo do Estado. Enquanto minoria, poloneses e brasileiros criaram laços de cumplicidade como forma de manter ajuda mútua contra os embates com os ucranianos.

Mas não podemos ser ingênuos em pensar que se tratava de rivalidade belicosa no sentido físico da palavra. Enquanto brasileiros e poloneses mantinham a hegemonia política, os ucranianos faziam valer suas representações coletivas e rechaçavam os que não compartilhavam delas.

Encaravam-se numa situação de descontentamento geral. Poloneses e ucranianos vivenciavam uma rivalidade construída ainda no além-mar (além de serem alocados distantes da sede) e brasileiros se viam prejudicados pela diminuição de suas terras com a chegada dos imigrantes. A rivalidade étnica parecia então sobrepor a fatores políticos, constituindo assim uma dicotomia - ucranianos e não ucranianos -que serviu de referência para a formulação da diferença.

Quando da divisão dos lotes, um formato diferenciado foi constituído. No processo de organização as terras destinadas a imigração foram divididas em linhas, formadas por diversas comunidades. Sobre as $\operatorname{linhas}^{8}$ e as comunidades que se formavam em seu núcleo Hauresko (2002) destaca

Essas comunidades possuem em seu entorno comunidades menores que se mantêm dependentes das comunidades-núcleos por meio de serviços de cunho social, econômico e cultural por elas oferecidos, são as comunidades simples. As famílias moradoras das comunidadesnúcleos usufruem de uma infra-estrutura própria (vendas, bares, igreja latina e igreja ucraniana, posto de coleta do correio, escolas, salões de festas, etc.). A relação entre as comunidades-núcleos e as comunidades simples pode ser interpretada como uma primeira diferenciação e hierarquização sócio-espacial. (HAURESKO, 2002, p. 66)

\footnotetext{
${ }^{7}$ Mal sabia o Governo Federal que Ucranianos e Poloneses já tinham rivalidades constituídas desde o século XVI, período em que a Ucrânia esteve sob o julgo do Império Polonês.

${ }^{8}$ As terras de Prudentópolis foram divididas em 38 linhas, sendo elas:ao norte: Rio dos Patos, Candido de Abreu, Nova Galícia, Cônsul Phol, Antonio Olinto, Barra Vermelha, Ivaí, Carlos Gomes, Luiz Xavier, Sertório, Santos Andrade, Vicente Machado, Guarapuava da Esperança, Paraná, Carlos Gomes, Piquiri, Capanema, Coronel Eduardo Chaves, Maurice Faivre, Sete de Setembro, União. E ao sul: Inspetor Carvalho, Rio Preto, Visconde de Nácar, Dezembro, Visconde de Guarapuava, XV de Novembro, Ponte Nova, Ponte Alta, Tiradentes, Jesuíno Marcondes $1^{\mathrm{a}}$ e $2^{\mathrm{a}}$ seção, Tijuco Preto, Coronel Bormann, Cláudio Guimarães, Vinte e Três de Abril, Ronda, Vinte e Cinco de Outubro e Taboãozinho. (KUSMA, 2002: p. 23)
} 
As linhas eram, na sua maioria, distantes da sede e das instituições públicas e religiosas que estavam em seu entorno, o que fez com que os imigrantes vissem a necessidade de constituir seus próprios espaços de sociabilidade. Atendendo a reivindicação dos imigrantes vieram para Prudentópolis padres católicos e ortodoxos que auxiliaram na construção desses espaços.

Imensas e ásperas foram as dificuldades com que depararam os primeiros imigrantes. Sem assistência efetiva dos poderes públicos, desconhecendo a língua do país, sem meios de transporte, sem estradas, sem ferramentas, desprovidos de recursos, desbravaram regiões incultas, arrotearam terras e fundaram cidades. Não podiam sequer pedir apoio de seus cônsules e embaixadores, pois não os tinham - filhos de uma grande nação, mas sem governo próprio. (WOUK, 1981: p. 35)

A falta de referência sentida pelos imigrantes foi suprida com a chegada dos padres que tenderam a valorizar os quadros tradicionais constituídos ainda no velho continente e que manteria assim, a união entre os integrantes do grupo étnico. Foi com essa valorização, em detrimento ao outro, que as principais representações coletivas estavam intimamente ligadas com a religião e a religiosidade, o que ajudou a direcionálas a construção/transformação de fronteiras identitárias.

Diante dos diferentes, os imigrantes buscaram elementos que lhes forneceram características capazes de diferenciar o grupo, de estipular uma fronteira ${ }^{9}$ étnica. Diante do outro encontrado em Prudentópolis como os brasileiros, por exemplo, os imigrantes se voltaram para a antiga pátria buscando elementos que os diferenciassem, produzindo assim formas de identificar os integrantes do grupo.

Numa batalha pela hegemonia imagética, indicada pela exaltação às tradições trazidas do velho continente, constantemente os imigrantes eram acusados de desrespeito a nacionalidade brasileira. Dentre essas tradições as religiosas parecem as que melhor traduzem a ligação entre os imigrantes e a instituição que não lhes havia abandonados durante a imigração: a Igreja. (RAMOS, 2012)

A partir dessa premissa, fica fácil compreender por que as principais representações coletivas que os grupos põem em prática são as religiosas e parece que é através delas que as batalhas imagéticas se travam.

\footnotetext{
${ }^{9} \mathrm{O}$ conceito de fronteira aqui sugerido é aquele discutido por Fredrik Barth em Grupos étnicos e suas fronteiras (1969).
} 
As famílias dos descendentes dos primeiros imigrantes mantinham, assim como aqueles, uma forte tradição religiosa. Muitas delas, pelo fato de não haver uma capela próxima das colônias em que residiam, deslocavam-se vários quilômetros de carroça ou até mesmo a pé, ainda no sábado, para poderem assistir a missa dominical na matriz da vila. (ZAROSKI, 2001, p. 35)

A rivalidade parecia ultrapassar os limites do imaginário quando fisicamente se travava uma concorrência na construção das igrejas. Como os grupos não se viam como iguais, as instituições são poderiam também ser. Dessa forma uma igreja latina era erguida quase em frete de uma ortodoxa. Dessa forma, ao percorrer as linhas coloniais em Prudentópolis é possível mensurar tal fenômeno.

O município de Prudentópolis soma um total de 130 comunidades rurais. Em praticamente todas elas encontram-se famílias de ucraínobrasileiros. A presença de ucranianos na comunidade pode ser apreendida quando há nesta uma igreja do rito-ucraíno-católico, um marco que indica a presença de um número considerável de famílias de ucraíno-brasileiros. (HAURESKO, 2002, p. 64)

Mesmo concorrendo pela constituição de uma identidade, o contato era inevitável e as relações tornaram-se cotidianas. A negociação dos quadros representativos da comunidade prudentopolitana caracterizou-se, cada vez mais, pelo viver nas comunidades. Esse convívio foi muito mais do que uma simples relação de vizinhança, pois resultou na criação ou (re)criação de elos que mantinham unido um grupo de pessoas. Formaramse esses elos por cultura em comum; as formas de consumo, a terra, a estrutura social e as normas comportamentais comuns estabelecidas pelo grupo, dentro de uma estrutura social comum, sistema hierárquico familiar e o valor da igreja. (RAMOS, 2012)

\section{PRUDENTÓPOLIS E A INTEGRAÇÃO ÉTNICA}

Com o passar das décadas o que era efeito da fronteira se transforma em integração. Porém, os desafios de compreender as relações interétnicas permanecem. De acordo com Eriksen (1993) o conceito de etnicidade está intimamente ligado ao de fronteira. Grupos étnicos podem ser semelhantes em sua forma cultural - língua, representações, alimentação, religiosidade - mas se pautarem sua vivência na diferença para com o outro a fronteira será definida. No caso de Prudentópolis podemos utilizar o exemplo de ucranianos e poloneses no em meados do século XX. 
O jogo da etnicidade que ucranianos, poloneses e brasileiros disputam caracterizase também nas semelhanças fenotípicas e culturais, pois acabam por alimentar uma crença subjetiva que estabelece uma comunidade ou grupo como tipo ideal. Através de lembranças da imigração ou da colonização e dos discursos que as acompanha é que essa crença acaba por se propagar entre os descendentes. Assim, alimentar a crença de que existe a necessidade de salvaguarda dos padrões culturais dos ascendentes parece propósito das instituições políticas, culturais, sociais e religiosas em Prudentópolis que com isso passa a impressão de que os indivíduos permanecem unidos em uma comunidade ancestral de pertença étnica. Levando em consideração as ideias de Poutignat (1998), as características que distinguem os grupos étnicos só terão eficácia na formulação de fronteiras se os diferentes grupos acreditarem que existe uma estranheza de origem, de preferência, distante.

A identidade étnica (a crença na vida em comum étnica) constrói-se a partir da diferença. A atração entre aqueles que se sentem como de uma mesma espécie é indissociável da repulsa diante daqueles que são percebidos como estrangeiros. Esta idéia implica que não é o isolamento que cria a consciência de pertença, mas, ao contrário, a comunicação das diferenças das quais os indivíduos se apropriam para estabelecer fronteiras étnicas. (POUTIGNAT, 1998, p. 40)

Como regra, o elemento diferenciador é construção do próprio grupo como, por exemplo, os ucranianos que se definiam como mais trabalhadores, éticos e ordeiros que os do lugar. Sustentavam o discurso de que enquanto europeus e brancos eram superiores. “Afirmando que a geografia (isto é, a natureza) era a base da raça, os imigrantes 'brancos' no Brasil criariam uma identidade nacional semelhante à europeia, que viria a esmagar, com sua superioridade, as populações nativas e africanas". (LESSER, 2001, p. 24)

Do outro lado dessa disputa, os brasileiros se diziam mais inteligentes e astutos e veem os imigrantes como um perigo para as relações sociais, econômicas e culturais existentes.

O imigrante representa para o autóctone alguém portador de diferença, da diversidade (física e cultural). A concepção de Estado-nação produzida na Europa ocidental criou a imagem de que os co-nacionais formam uma parentela alargada (ainda que seja constituída de milhões de pessoas diferentes). Desse modo, o imigrante aparece como estrangeiro; no caso em questão, como inferior intelectual e moralmente, portanto, perigoso e culpado por contaminar a cultura hospedante. (TEDESCO, 2004, p. 99) 
O processo de constituição do espaço prudentopolitano, tanto a vila quanto a colônia, forçavam ao contato e ao relacionamento. Os imigrantes em Prudentópolis buscavam em vilarejos vizinhos as ferramentas que necessitavam para realizar seus trabalhos e suas plantações ${ }^{10}$. Buscavam também a confiança dos negociantes que compravam seus produtos, definindo os limites não apenas pelos valores culturais, mas também levando em consideração os fatores econômicos e políticos.

O contexto da criação do município visto anteriormente é o suficiente para afastar a teoria do isolamento geográfico, tese reforçada com chegada de diferentes grupos étnicos. Encontros a caminho de casa, da venda, da igreja se tornavam cada vez mais frequentes, ocasionando relacionamentos de aproximação ou de distanciamento, mas sem dúvida, de contato.

O sentimento de estranheza ocorreria principalmente com os imigrantes que eram tidos como invasores pelos do lugar, mas não era exclusividade deles.

A etnicidade, então, refere-se aos grupos, ou mais exatamente aos povos, que são nações potenciais, situadas em um estágio preliminar da formação da consciência nacional. Neste estágio, a solidariedade étnica manifesta-se no confronto com elementos estrangeiros e originase na xenofobia, sem por isso constituir uma pertença consciente de si própria e dotada de uma significação positiva. Um grupo étnico é então "simplesmente" uma categoria descritiva e objetiva, discernível pelo observador externo. (POUTIGNAT, 1998, p. 45)

Tal análise também cabe para definir a rivalidade entre ucranianos e poloneses que perdurava gerações e que veio junto ao Brasil pela migração desses povos ${ }^{11}$. Foi na tentativa de afastar o outro que os imigrantes se apegavam as antigas nações e tradições, o que por muitas vezes criava, entre os brasileiros, a sensação de que aqueles enalteciam a pátria de origem em detrimento ao Brasil.

Parecia comum, entre os imigrantes principalmente, atribuir à nova terra um sentimento de continuidade histórica embasada nos mitos de origem de sua antiga nação,

${ }^{10}$ Segundo Zaroski (2001), os primeiros anos dos imigrantes ucranianos e poloneses em solo paranaense não foram nada fáceis, visto que o governo apenas lhes "concedia" as terras, sendo o dinheiro escasso e não havendo a possibilidade, nem a vontade, de regressarem para seu país de origem.

${ }^{11}$ Com base nas semelhanças os agentes de colonização buscavam aproximar grupos parecidos e harmoniosos, sem compreender as relações históricas entre esses dois grupos que em diversos momentos formaram grupos antagônicos, pois a Ucrânia esteve durante séculos sobre o subjugo polonês. 
o que propiciava o ambiente perfeito para o embate. Ucranianos e poloneses por vezes pareciam estar ainda na Europa do século XVIII. De acordo com Poutignat (1998) “nenhuma nação moderna possui uma base 'étnica' dada... o problema fundamental é portanto o de produzir o povo: ou, melhor, é que o povo, ele mesmo, se produza em permanência como comunidade nacional".

Tal permanência e manutenção, dos usos e costumes e representações coletivas, por exemplo, acirrava o sentimento de rivalidade, pois os não ucranianos constantemente os acusavam de ameaçar a nacionalidade brasileira. Tal afirmação reforçava o sentimento de repúdio e consequentemente o de representação de si e do outro, fazendo com que a diferença estabelecida entre os grupos étnicos fosse constantemente formadora da relação de diferença simbólica. (RAMOS, 2008)

A rivalidade tradicional entre os dois povos eslavos, de origem histórica e não social, continuou a se fazer sentir mesmo longe do campo de luta em que ambos se digladiaram por vários séculos. Hoje, porém, somente os mais velhos não esquecem e não perdoam o fato dos poloneses haverem reduzido o povo ucraíno ao estado de servidão, depois de o haverem despejado das suas liberdades políticas. (WOUK, 1981, p. 23)

Essa rivalidade contribuiu para a construção/transformação de um imaginário coletivo prudentopolitano, havendo tentativas de predominância que se constantemente se valiam de representações de poder.

Tal poder poderia ser representado, no caso dos ucranianos, pela imposição, manutenção e difusão de suas formas de identificação, algo possível pelo fato de ser o grupo mais numeroso. A língua, alimentação, ritos são alguns exemplos. Por outro lado tem-se, por poloneses e brasileiros, o poder instituído no município, como já citado anteriormente.

O fato de ser maioria em Prudentópolis não garantiu, a princípio, um lugar ao sol aos grupos imigrantes. Ficaram décadas a margem da história do local. O discurso sobre o imaginário coletivo parecia monopólio daqueles que demonstravam uma afinidade com o Governo do Estado e demais poderes constituídos.

A preocupação do imigrante não parecia tentar dominar o espaço político no município, mas suas ações eram sentidas no campo da longa duração. Seus usos, costumes e as representações coletivas acabavam por povoar as ações cotidianas, constituindo assim o imaginário prudentopolitano. 
os poderes que conseguem garantir o controle, senão o monopólio destes meios, apropriam-se assim de uma arma tanto mais temível quanto mais sofisticada. É difícil subestimar as possibilidades que se abrem, deste modo, às iniciativas de tipo totalitário que visam anular os valores e modelos formadores diferentes daqueles que o Estado deseja, bem como condicionar e manipular as massas, bloqueando a produção e renovação espontânea dos imaginários. (BACZKO, 1985, p. 308)

Mesmo sem o intuito de controlar o espaço imagético seus símbolos e representações foram sendo gradativamente utilizadas para a construção de fronteiras identitárias. A forma, mesmo que inconsciente, de garantir o monopólio do imaginário coletivo estava visível nos espaços públicos e privados. Em todos os lugares era possível perceber atividades cotidianas que envolviam usos e costumes de cada grupo, fazendo com que cada vez mais indivíduos reconhecessem esses fazeres. Tal ação dava a impressão de que esses indivíduos consideravam essas representações como tradicionais e, principalmente, os faziam se considerar como parte integrante dessa tradicionalidade.

o domínio do imaginário é constituído pelo conjunto das representações que exorbitam do limite colocado pelas constatações da experiência e pelos encadeamentos dedutivos que estas autorizam (...). Em outras palavras, o limite entre o real e o imaginário revela-se variável, enquanto que o território atravessado por este limite permanece, ao contrário, sempre e por toda a parte idêntica, já que nada mais é senão o campo inteiro da experiência humana, do mais coletivamente social ao mais intimamente pessoal. (PATLAGEAN, 1994, p. 291)

Para analisar o imaginário popular prudentopolitano tem-se que buscar informações na base de sua estrutura, pois é a partir dessas informações que é possível identificar o sistema simbólico criado para a construção de fronteiras e dessa forma para o processo de integração. (RAMOS, 2012)

A conceitualização de fronteira étnica estaria então pautada na diferença, que no caso de Prudentópolis parece ter sido criada antes mesmo da imigração dos grupos eslavos. É uma memória coletiva que acompanhou ucranianos e poloneses até terras brasileiras. Mas não podemos deixar de pensar que muita dessa memória condicionada pelo passado contém elementos do presente para se legitimar, pois "todos os seres humanos, coletividades e instituições necessitam de um passado" (HOBSBAWM, 1994, p. 283). Com base no condicionamento dessa memória os grupos étnicos criaram formas de se identificar, criando fronteiras frente ao outro. 
Mas quem é esse outro? Seu vizinho, a pessoa a sua frente na fila do banco, seu colega de escola e outros milhares de indivíduos que cotidianamente estão a sua frente.

\begin{abstract}
Situações de contato social entre pessoas de culturas diferentes também estão implicadas na manutenção da fronteira étnica: grupos étnicos persistem como unidades significativas apenas se implicarem marcadas diferenças no comportamento, isto é, diferenças culturais persistentes. Contudo, onde indivíduos de culturas diferentes interagem, poder-seia esperar que tais diferenças se reduzissem, uma vez que a interação simultaneamente requer e cria uma congruência de códigos e valores. (BARTH, 1969 apud POUTIGNAT, 1998, p. 196)
\end{abstract}

Com esse contato se percebe que a identidade é dinâmica e está em constante movimento e somente o contato no demonstra isso. Essa interação transcende os aspectos culturais do interior do grupo, envolvendo as imagens e representações dos que os circundam. Pensar a identidade étnica e sua construção seria então uma característica de ordem social que tende a se transformar através do contato. (RAMOS, 2006)

Através dessa afirmação é possível definir o processo de integração étnica, visto que o cotidiano de uma comunidade é definido pelo processo de assimilação pelo grupo das representações coletivas de grupos distintos, sendo a recíproca verdadeira. Por isso explicá-los separadamente seria um grave erro, pois é evidente a existência de uma estreita relação entre os diferentes níveis de identidade.

Assim vislumbrou-se ucranianos e suas relações com outras etnias através de comparativos sociais, já que a identidade ucraniana não é original em sua totalidade, mas sim uma tradução de imagens e representações que se tornam tradição. Os ucranianos em Prudentópolis dentre muitos de seus usos e costumes não apresentam fazeres de origem particularmente ucraniana, mas sim polonesa, austríaca, russa. Com isso "um grupo pode adotar os traços culturais de outro, como a língua e a religião, e contudo continuar a ser percebido e a se perceber como distintivo”. (POUTIGNAT, 1998, p. 156)

Esse processo de identificação está sujeito a várias construções, transformações e influências num processo constante. Cabe a cada indivíduo ou coletividade fazer o processo de identificação e resguardar os valores que os diferenciam dos outros. Esses processos de identificação, ou melhor, de construção/transformação de identidade podem ser feitos de diversas maneiras, dependendo do grupo a que pertencem ou pretendem pertencer.

O contato com o outro determinaria, a priori, a troca de experiências e valores no momento em que exista a necessidade de transpor a fronteira étnica com o intuito 
de manter um relacionamento de simbiose com seus vizinhos, os quais diversas vezes partilham de um imaginário cultural semelhante, mas que são tidos como diferentes pela maneira de se identificar. (RAMOS, 2006)

\section{CONSIDERAÇÕES FINAIS}

Diferentes frente a frente. É esse o contexto, decorrente da "ocupação do espaço", que ucranianos, poloneses e brasileiros estão inseridos. É nesse cenário que o cotidiano, fazeres, usos e cotumes, representações coletivas e o imaginário ocupam nova dimensão para a história de Prudentópolis. Com isso poderíamos cair na tentação de pensar a construção do imiginário prudentopolitano a partir de composições isoladas. Primeiramente o ucraniano, repleto de desconfiança e busca pelo distanciamento frente o outro. O polonês, criando suas fronteiras para com os ucranianos, e os brasileiros mantenedores das noções de pertencimento de nacionalidade brasileira.

Mas temos que pensar que o contato criou laços que gradativamente constituía o processo de integração étnica. Não foi o fato de estar em um novo mundo que faria com que indivíduos perdessem sua ascendência ucraniana ou polonesa. $\mathrm{O}$ contato propiciado pela adequação do espaço definiu os novos padrões identitários. Não foi somente o fato de ser ucraniano ou polonês que definiu a identidade desses indivíduos, mas o fato de ser ucraniano e polonês em terras prudentopolitanas e em contato direto com o outro. (RAMOS, 2012)

A rivalidade entre os de ascendência eslava era anterior a imigração e foi formada por fissão e não por fusão. Foi o contato que reacendeu antigos ranços. Não estavam na Ucrânia e nem na Polônia, mas numa realidade alheia e hostil chamada Prudentópolis.

Em Prudentópolis já existia luta pela hegemonia local, pois sertanejos e indígenas já determinavam o ritmo do lugar. Um ritmo desacelerado regia o tempo dos viventes e esse ritmo foi modificado com a chegada dos imigrantes que tornaram Prudentópolis, local de luta simbólica pela hegemonia dos padrões culturais constituidores da identidade local.

Como o contato era inevitável aos poucos as fronteiras tomavam novos limites. A negociação das identidades estava presente nas ações cotidianas. Nessa negociação é impossível afirmar qual grupo mais assegurou valores ancestrais e esse nunca foi a intenção desse ensaio. Mas é possível pensar a mistura e miscigenação cultural criada por essa negociação. É nos lugares praticados: no entrecruzamento das pessoas na rua, na calçada, na missa, nas lojas, nos enterros de conhecidos, escolas e em tantos outros locais 
de práticas de relações cotidianas que se construíram novas formas de entrecruzamentos culturais. (RAMOS, 2012)

Assim, a constituição da identidade prudentopolitana teve como base a negociação das identidades ucranianas, polonesas e "brasileiras", sendo que a negociação da identidade pode ser compreendida como mecanismo que define os padrões de uma nova identidade, formada a partir da apropriação de padrões culturais distintos e que paulatinamente formam um novo tipo ideal.

Sobretudo, parece-nos realmente que em Prudentópolis a prática cotidiana levou à destruição das antigas identidades étnicas isoladas, fechadas em si, para criar uma grande identidade coletiva, um imaginário social onde, não sem conflitos, se estabeleceu uma nova identidade, imaginada e praticada, do povo de Prudentópolis. 


\section{REFERÊNCIAS:}

BACZKO, Bronislaw. A Imaginação social In: Enciclopédia Einaudi:Anthropos Homem. v. 5. Lisboa: Imprensa Nacional/Casa da Moeda, 1985. p. 296-332.

BARTH, Fredrik. "Grupos étnicos e suas fronteiras". In: POUTIGNAT, P. \& STREIFFFENART, J. Teorias da etnicidade, seguido de Grupos étnicos e suas fronteiras, de Fredrik Barth. São Paulo: Editora da Unesp, 1998.

BURKO, Pe. Valdomiro. A imigração Ucraniana no Brasil. Padres Brasilianos. Curitiba: [s.n.], 1963.

CAMARGO, Affonso Alves de. Homenagem do município de Prudentópolis. Prudentópolis: [s.n.], 1929.

DREHER, Martin. O fenômeno imigratório alemão para o Brasil. Estudos Leopoldenses, São Leopoldo, v. 31, n. 142, maio/jun.1995.

ERIKSEN, Thomas Hylland. Ethnicity \& Nationalism. Anthropological Perpectives. London: Pluto Press, 1993.

HAURESKO, Cecília. Organização sócio-espacial das familias de ucraíno-brasileiros em comunidades rurais do município de Prudentópolis -PR. Guarapuava: Guairacá, 2002.

HOBSBAWM, Eric J.; RANGER, Terence. (Orgs). A invenção das tradições. Rio de Janeiro: Paz e Terra, 1994.

KUSMA, Rita. Ritos tradicionais de casamento nas comunidades ucranianas do interior de Prudentópolis: 1920-1930. 53 f. Monografia (Graduação em História) - Unicentro, Guarapuava - Pr, 2002.

LESSER, Jeffrey. A negociação da identidade nacional: imigrantes, minorias e a luta pela etnicidade no Brasil. São Paulo: Editora UNESP, 2001.

MENEZES, Marluci. Do espaço ao lugar: do lugar às remodelações sócioespaciais. Horizontes Antropológicos, Porto Alegre, v. 6, n. 13, p. 156-175, jun. 2000.

PARANÁ. Presidente de Província (1857-1859:Mattos). Relatório do presidente da província do Paraná Francisco Liberato de Mattos na abertura da Assembleia Legislativa Provincial em 7 de janeiro de 1858. Curityba: Typ. Paranaense de C. Martins Lopes, 1858. p. 21. 
PARANÁ. Presidente de Província (1882-1883: Carvalho). Relatório do presidente da província do Paraná Carlos Augusto de Carvalho por ocasião da instalação da $1^{a}$ secção da $15^{a}$ legislatura em 1 de outubro de 1882. Curityba: Typ. Paranaense Perseverança de J. F. Pinheiro, 1882. p. 74.

PATLAGEAN, Evelyne. A história do Imaginário. In: GOFF, Le. A Nova História. São Paulo: Martins Fontes, 1994.

POCZENCK, Eugênia. Linha Esperança: o ontem e o hoje. Linha Esperança: Relatório, 1998.

POUTIGNAT, Philippe. Teorias da Etnicidade: seguido de grupos étnicos e suas fronteiras de Fredrik Barth. São Paulo: Editora UNESP, 1998.

RAMOS, Odinei Fabiano. Ucranianos, poloneses e "brasileiros": fronteiras étnicas e identitárias em Prudentópolis/PR. Dissertação (Mestrado em História) - Escola de Humanidades, UNISINOS, São Leopoldo, 2006.

RAMOS, Odinei Fabiano. Experiências da colonização eslava no centro-sul do Paraná (Prudentópolis 1895-1995). 218 f. Tese (Doutorado em História) - Faculdade de Ciências Humanas e Sociais, Universidade Estadual Paulista Júlio de Mesquita Filho, Franca, 2012.

TEDESCO, João Carlos.Nas cercanias da memória: temporalidade, experiência e narração. Passo Fundo: EDUCS, 2004.

WACHOWICZ, Rui Christovam. História do Paraná. 10 ed. Ponta Grossa: UEPG, 2010.

WOUK, Miguel. Estudo Etnicográfico-linguístico da Comunidade Ucraniana de Dorizon. Curitiba: Editora Projeto, 1981.

ZAROSKI, Nelson Gilmar. A utilização do tempo pelos imigrantes ucranianos de Prudentópolis: 1940-1960. [Prudentópolis]: Gráfica Prudentópolis, 2001. 